\title{
TU/e emonown

\section{Probabilistic fatigue life updating accounting for inspections of multiple critical locations}

Citation for published version (APA):

Maljaars, J., \& Vrouwenvelder, A. C. W. M. (2014). Probabilistic fatigue life updating accounting for inspections of multiple critical locations. International Journal of Fatigue, 68, 24-37.

https://doi.org/10.1016/j.ijfatigue.2014.06.011

DOI:

10.1016/j.ijfatigue.2014.06.011

Document status and date:

Published: 01/01/2014

\section{Document Version:}

Publisher's PDF, also known as Version of Record (includes final page, issue and volume numbers)

\section{Please check the document version of this publication:}

- A submitted manuscript is the version of the article upon submission and before peer-review. There can be important differences between the submitted version and the official published version of record. People interested in the research are advised to contact the author for the final version of the publication, or visit the $\mathrm{DOI}$ to the publisher's website.

- The final author version and the galley proof are versions of the publication after peer review.

- The final published version features the final layout of the paper including the volume, issue and page numbers.

Link to publication

\section{General rights}

Copyright and moral rights for the publications made accessible in the public portal are retained by the authors and/or other copyright owners and it is a condition of accessing publications that users recognise and abide by the legal requirements associated with these rights.

- Users may download and print one copy of any publication from the public portal for the purpose of private study or research.

- You may not further distribute the material or use it for any profit-making activity or commercial gain

- You may freely distribute the URL identifying the publication in the public portal.

If the publication is distributed under the terms of Article 25fa of the Dutch Copyright Act, indicated by the "Taverne" license above, please follow below link for the End User Agreement:

www.tue.nl/taverne

Take down policy

If you believe that this document breaches copyright please contact us at:

openaccess@tue.nl

providing details and we will investigate your claim. 


\title{
Probabilistic fatigue life updating accounting for inspections of multiple critical locations
}

\author{
J. Maljaars ${ }^{\mathrm{a}, \mathrm{b}, *}$, A.C.W.M. Vrouwenvelder ${ }^{\mathrm{a}}$ \\ a TNO, P.O. Box 49, 2600 AA Delft, The Netherlands \\ ${ }^{\mathrm{b}}$ Eindhoven University of Technology, Den Dolech 2, 5612 AZ Eindhoven, The Netherlands
}

\section{A R T I C L E I N F O}

\section{Article history:}

Received 8 April 2014

Received in revised form 17 June 2014

Accepted 19 June 2014

Available online 30 June 2014

\section{Keywords:}

Fracture mechanics

System reliability

Bayesian updating

Inspection planning

Orthotropic bridge deck

\begin{abstract}
A B S T R A C T
Many steel structures contain multiple fatigue sensitive details that have similar geometries and are subjected to similar load fluctuations. Examples are orthotropic (bridge) decks and stiffened (ship) hulls where tens to thousands of similar details are present in one structure. Generally only visual inspections on fatigue cracks are considered for these structures because more accurate techniques are considered to be too expensive and time consuming when so many details need to be inspected. Visual inspections are known to have a low probability of detection. Consequently Bayesian update techniques usually show a marginal effect of the result of visual inspections on the reliability of structures with respect to fatigue failure. On the other hand the inspection result of one location also provides information on similar details at other locations and thus the significance of the inspection result may be larger if multiple potential crack locations occur and cracks are not detected at any of these locations. This paper provides a probabilistic fatigue crack growth (fracture mechanics) model of a system containing a fatigue sensitive detail at multiple locations that accounts for the results of inspections. Spatial correlations of loading, resistance, and uncertainty variables between the different locations are evaluated and estimated through a literature review and are accounted for in the model. The model is demonstrated on a practical example of an orthotropic bridge deck containing a detail at 100 locations. The paper shows that visual inspections may be effective provided that a certain minimum inspection reliability can be guaranteed, that the structure is relatively tolerant to large cracks, and that the geometry and loading conditions are similar for a large number of locations.
\end{abstract}

(c) 2014 Elsevier Ltd. All rights reserved.

\section{Introduction}

Worldwide there is a main challenge in maintaining existing infrastructures and offshore structures. One of the main failure mechanisms of steel structures is fatigue [1]. Replacement or even upgrading of structures for which initial calculations indicate that the design life has expired is in many cases not necessary. Instead it is possible to evaluate the current state of the structure on the basis of fatigue inspections. If cracks are not found or if detected cracks are repaired, the structure may be fit for use.

Probabilistic models are put forward in literature dedicated to the evaluation and updating of the reliability of inspected structures, e.g. [2-7]. The general approach followed in these studies is using inspection results to update the initial belief of the governing variables of a crack growth (fracture mechanics) model using

\footnotetext{
* Corresponding author at: TNO, P.O. Box 49, 2600 AA Delft, The Netherlands. Tel.: +31 888663464 .

E-mail address: johan.maljaars@tno.nl (J. Maljaars).
}

the Bayesian theorem, [8]. The models are used to determine the time interval to the subsequent inspections e.g. for offshore structures $[9,10]$ and aircraft structures [11].

The general principle of the methods in the above mentioned studies is explained in Fig. 1. This figure provides the crack size, $a$, on the vertical axis as a function of the time, $t$, on the horizontal axis. The crack grows in time due to the fluctuating loads from an initial defect with size $a_{0}$ to a final crack size, $a_{f}$. Due to the wide distributions of the variables that determine the crack growth, $[12,13]$, the scatter in the crack growth is relatively large (light grey area) and consequently the scatter in fatigue life is large (light grey distribution). If an inspection is carried out using an inspection technique with a detection limit, $a_{d}$, it is possible to update the probability density functions of the variables based on the inspection result. This reduces the scatter in crack growth, especially at the lower bound of the determined life (dark grey area and distribution). Based on the updated crack growth prediction it is possible to determine the required interval to the next inspections. 


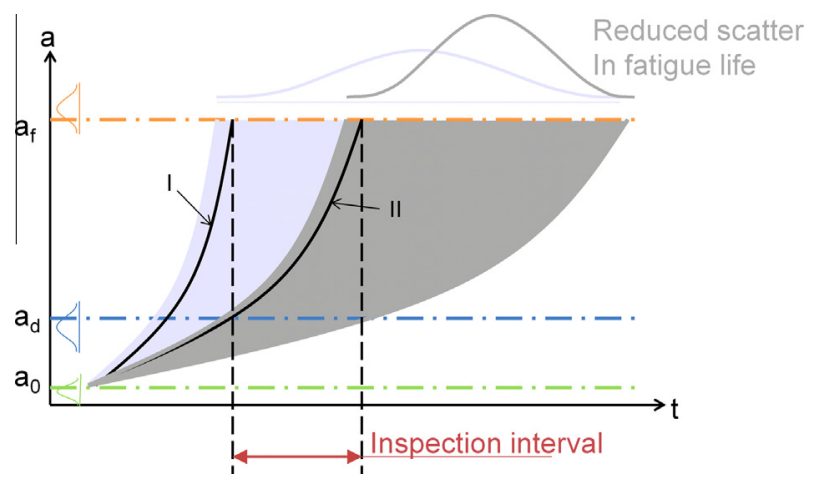

Fig. 1. Principle of fatigue life updating through considering inspection result with crack size, $a$, as a function of time, $t$. Curve I: $x \%$ probability of exceeding without inspection (prior). Curve II: $x \%$ probability of exceeding accounting for the inspection result (posterior).

Most structures contain multiple fatigue sensitive details. A number of authors have considered multiple details in probabilistic crack growth models accounting for inspection results. Kim and Frangopol [14] and Soliman et al. [15] have developed probabilistic methods for cost-optimised inspections of structures containing more than one critical details. Rabiei and Modarres [16] have developed a method that considers information from multiple sources such as physical models, monitoring data, and inspections, to update the fatigue life prediction. Variations on the classical fracture mechanics crack growth model [17] have been developed, such as models accounting for stress ratios and load sequence effects in variable amplitude loading, [18,19]. Guan et al. [20] have provided a framework for fatigue failure in which the most appropriate of these models and their variables are selected and updated using the Bayesian theorem.

Studies considering visual inspections in updating the reliability are rare due to the poor probability of detection of this method, [21], which generally results in short inspection periods. However, in practice visual inspections are often applied because of the relatively low costs involved. Especially for structures with fatigue sensitive details that occur multiple times in that structure - hundreds or thousands - more advanced inspection methods are often considered too expensive and too time consuming. Examples of such structures are welded orthotropic bridge, ship, or platform decks with deck plate, stringer and crossbeam connections or stiffened ship hulls.

Most of the previous studies considered one detail at a time. In case of details at multiple locations in a structure - with similar geometry and similar loading - one can make use of spatial correlations between the underlying variables of the crack growth mechanism. In comparison with an inspection of a single detail without a detected crack, the significance of the inspection result may be larger if multiple potential crack locations occur and cracks are not detected at any of these locations. Visual inspection may be feasible in such cases. An alternative is to inspect a certain fraction of all locations using more advanced inspection methods.

Spatial correlations have been considered in a number of studies. Feng et al. [22] studied the influence of spatial correlations between the power law approximations of the stress intensity factors of two types of crack in a stiffened panel. Their results show the importance of spatial correlations on the failure probability of a parallel system. Sørensen and Ersdal [23] have shown that a high degree of correlation between the uncertain parameters in different components is needed in order to obtain substantial information which can be used in inspection planning. Moan and Song [24] have studied the influence of inspection updating on the fatigue failure probability of a series system. Uraga and Moan
[25] have considered the fatigue reliability of a parallel system consisting of 2 joints. They have mentioned the qualitative influence of spatial correlations but have not implemented these in their analyses. All these studies considered a small number of details or locations.

This paper provides a method to determine the reliability of a structure considering fatigue failure of a detail repeated multiple times in that structure, where spatial correlations are accounted for. The method is demonstrated for the case of an orthotropic bridge deck. The influence of various inspection strategies on the reliability of the bridge deck structure - including visual inspections - are provided.

\section{Fatigue crack growth (fracture mechanics) model}

\subsection{General fracture mechanics procedure}

The crack growth model used is based on classical fracture mechanics (FM). The principles of the method are described in many articles and books - such as [26,27] - and are briefly summarised hereafter.

The stress intensity factor, $K$, is a basic parameter in FM and represents the stress state in the vicinity of the crack tip caused by a remote load. In case of a semi-elliptical surface crack at the toe of a weld, Fig. 2, the stress state is usually represented by the stress intensity factor at the deepest point, $K_{a}$, and the stress intensity factor at the surface, $K_{c}$. For a given geometry and loading, the stress intensity factors are derived either analytically or by the finite element method and are often expressed by equations. In this paper, the following expressions are used:

$$
\begin{aligned}
& K_{a}=\left(s_{m} Y_{m a} M_{m a}+s_{b} Y_{b a} M_{b a}\right) \sqrt{\pi a} \\
& K_{c}=\left(s_{m} Y_{m c} M_{m c}+s_{b} Y_{b c} M_{b c}\right) \sqrt{\pi a}
\end{aligned}
$$

where $s$ is the remote stress, $a$ is the crack depth, $Y$ is the geometry correction factor for a semi-elliptical surface crack or a through thickness crack, $M$ is the geometry correction factor for a weld toe (both correction factors are addressed hereafter), subscripts $m$ and $b$ indicate membrane loading and bending loading, respectively, and subscripts $a$ and $c$ indicate the surface and deepest points, respectively.

The FM model for fatigue crack growth makes use of the empirical relationship between the ranges of the stress intensity factors, $\Delta K_{a}$ or $\Delta K_{c}$, and the crack size increment per cycle, $\mathrm{d} a / \mathrm{d} N$ or $\mathrm{d} c / \mathrm{d} N$, where $a$ is the crack depth and $c$ is the semi crack width, Fig. 2, and $N$ is the number of stress cycles. The empirical relationship used in this paper is the 2 stage curve provided in BS 7910:2013 [28]. In depth direction, the relationship is expressed as (Fig. 3):

$$
\frac{\mathrm{d} a}{\mathrm{~d} N}\left(\Delta K_{a}\right)=\left\{\begin{array}{lll}
0 & \text { if } & \Delta K_{a} \leqslant \Delta K_{0} \\
A_{1}\left(\Delta K_{a}\right)^{m_{1}} & \text { if } & \Delta K_{0}<\Delta K_{a} \leqslant\left(\frac{A_{2}}{A_{1}}\right)^{\frac{1}{m_{2}-m_{1}}} \\
A_{2}\left(\Delta K_{a}\right)^{m_{2}} & \text { if } & \Delta K_{a}>\left(\frac{A_{2}}{A_{1}}\right)^{\frac{1}{m_{2}-m_{1}}}
\end{array}\right.
$$

where $A_{1}, A_{2}, m_{1}, m_{2}$, and $\Delta K_{0}$ are empirical, material related variables. A similar expression is used for the width direction, $\mathrm{d} c / \mathrm{d} N$ versus $\Delta K_{c}$. Eq. (1) is substituted into Eq. (2) and an incremental numerical integration procedure is carried out in which the relationships between the number of stress cycles, $N$, and the crack size parameters, $a$ and $c$, are determined. The procedure starts at an initial, representative defect of a welded structure prior to loading, expressed with $a_{0}$ and $c_{0}$, and ends at the attainment of a final or critical crack size, expressed with $a_{f}$ and/or $c_{f}$.

The expressions for $Y$ and $M$ in Eq. (1) are a function of the crack size, expressed by $a$ and $c$, the plate thickness, $T$, and the node 


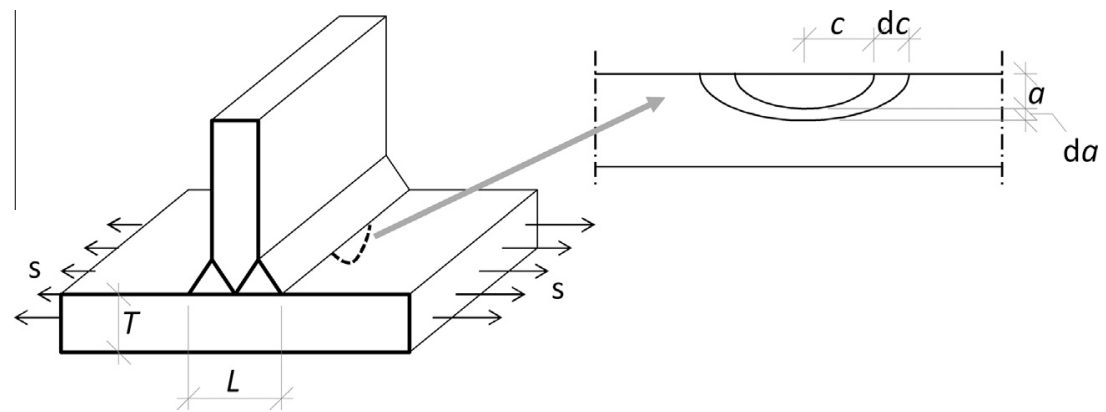

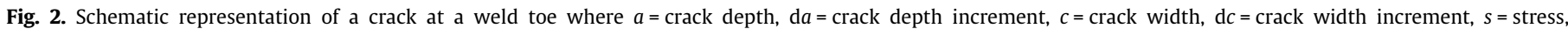
$T=$ thickness and $L=$ node length.

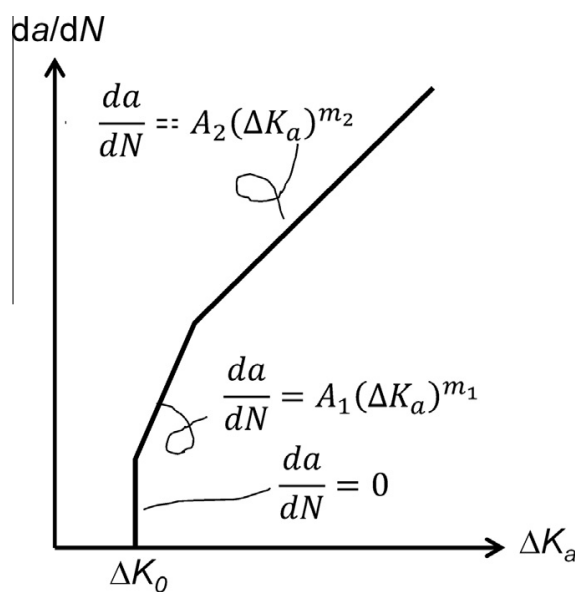

Fig. 3. Empirical crack growth law with crack growth rate, $\mathrm{d} a / \mathrm{d} N$, as a function of stress intensity range, $\Delta K_{a}$, with empirical variables $A_{1}, A_{2}, m_{1}, m_{2}$, and $\Delta K_{0}$.

length, $L$ (Fig. 2). The expressions provided in [29] have been used for $M$. The expressions for $Y$ in [30] have been used for a semi-elliptical surface crack, up to the attainment of a surface breaking crack. From this moment onwards the procedure in BS 7910:2013 [28] is applied, which consists of the following steps:

1. A through-thickness crack with a straight crack front is assumed. The straight fronted crack length is equal to the width of the semi-elliptical surface breaking crack, Fig. 4. Note that this is a conservative approximation.

2 . The crack may subsequently grow in length direction, where the control parameter, $a$, is now the semi crack length, and $Y=1$. Note that the choice of $Y=1$ is a conservative approximation in case the plate is (predominantly) loaded in bending.

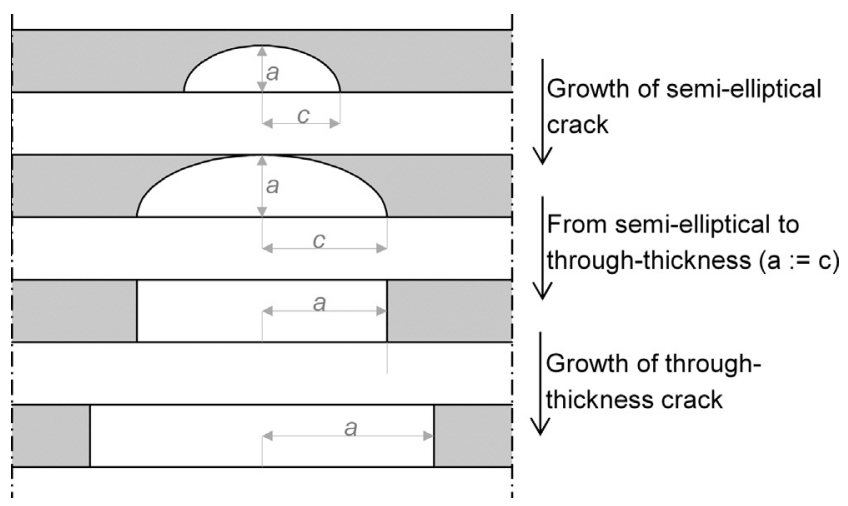

Fig. 4. Crack growth procedure from semi-elliptical to central through cracks.
The calculation ends at the attainment of a final crack length
$2 a_{f}$.

\subsection{Type of crack considered}

Various types of crack have been observed in orthotropic bridge decks. An overview of details with cracks observed in practice is provided in Leendertz [31], Fig. 5a. The current paper considers the crack in detail S.4.2 as an example to explain the procedure, Fig. 5b. This crack starts from the weld toe at the trapezoidal stringer side of the weld between a continuous stringer and a discontinuous crossbeam. The number of locations below the wheel tracks with this detail typically varies between 10 to more than $10^{3}$ in one bridge, depending on the span of that bridge.

A comparison between the FM model and fatigue experiments on detail S.4.2 is carried out for validation purposes. Only one test campaign on detail S.4.2 with a limited number of results is available from literature. Beales [32] has carried out constant amplitude tests on continuous stringer-to-crossbeam joints with V-shaped stringers and some of the tests showed cracks at detail S.4.2. The results of the tests are presented as the stress range, $\Delta s$, versus the number of cycles to failure, $N_{f}$, in Fig. 6. The figure also presents the results of two sets of FM calculations with the model presented in this section. The first set is carried out with average values of variables, $\mu$, and the second set is carried out with design values, $X_{d}$, where average and design values are provided in Table 1 (variables $1-5,7-9$, 11 and 12). The sources of the values in Table 1 are provided later in this paper. An analysis with the finite element method of detail S.4.2 indicated that the stress range, $\Delta s$, is composed of a combination of membrane and bending stress where $\Delta s_{m}=0.4 \Delta s$ and $\Delta s_{b}=0.6 \Delta s$. This has been considered in the FM calculations. Fig. 6 indicates that the results of the FM calculations using average values for all variables agrees with the test results, although the number of test results is too small for a sound validation of the FM model.

\section{Probabilistic model for a set of details}

\subsection{Limit state function for 1 location without inspection}

The FM model is implemented in a probabilistic framework where the load and resistance parameters such as $s_{m}, s_{b}, T, L, a_{0}$, $c_{0}, A_{1}, A_{2}$ and $\Delta K_{0}$ are considered as random variables. The stress intensity ranges in the probabilistic FM model are slightly modified versions of the stress intensity factors of Eq. (1). Assuming a stress histogram consisting of $n_{\text {tot }}$ stress cycles of variable amplitude, the stress intensity ranges for each of the $k=1 \ldots n_{\text {tot }}$ cycles is obtained with: 

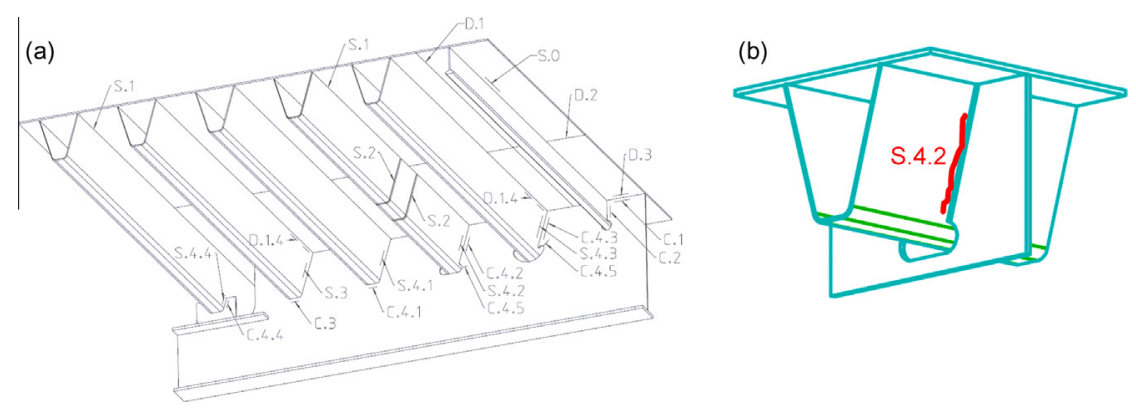

Fig. 5. Considered crack location. (a) Overview of crack locations in an orthotropic bridge deck (source: Leendertz [33]). (b) Crack S.4.2.

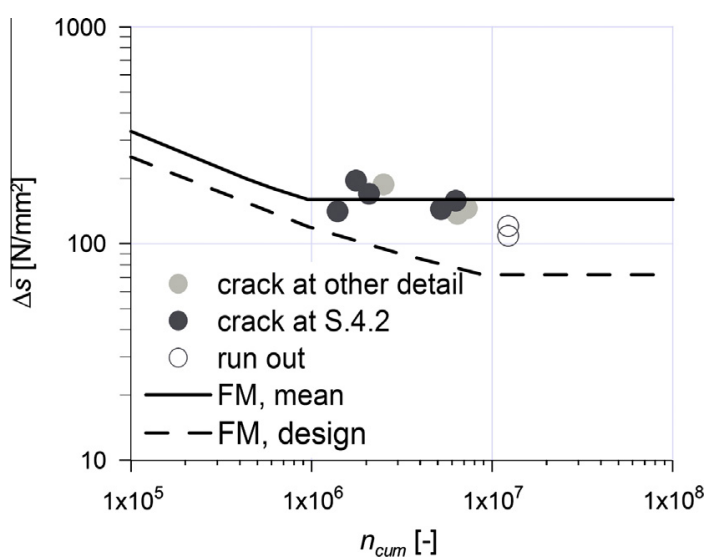

Fig. 6. Comparison of FM calculations with tests of Beales [34] for constant amplitude loading on detail S.4.2 of Fig. 5b.

$$
\begin{aligned}
& \Delta K_{a k}=\delta C\left(\frac{T_{n o m}}{T}\right)\left(\Delta s_{m k} Y_{m a} M_{m a}+\Delta s_{b k} Y_{b a} M_{b a}\right) \sqrt{\pi a} \\
& \Delta K_{c k}=\delta C\left(\frac{T_{n o m}}{T}\right)\left(\Delta s_{m k} Y_{m c} M_{m c}+\Delta s_{b k} Y_{b c} M_{b c}\right) \sqrt{\pi a}
\end{aligned}
$$

where $T$ is the plate thickness (Fig. 2), $T_{\text {nom }}$ is the nominal plate thickness used in the stress range calculation, $\delta$ is a stress multiplier accounting for dynamic effects that are excluded from the stress range calculation, and $C$ is an uncertainty factor accounting for model uncertainty and scatter in the loading, in the stress analysis and in the expressions of the geometry correction factors, $Y$ and $M$. Because retardation and other sequence effects are ignored in this paper, it is possible to apply a cycle counting procedure and the stress histogram can be divided into blocks with stress ranges, $\Delta s_{k}$, and annual number of cycles, $n_{k}$, in each block $k$. The stress intensity ranges for block $k$ are evaluated using Eq. (3).

Assuming a sufficiently mixing (ergodic) process for $\Delta s-$ which is a reasonable assumption for bridge decks loaded by vehicles and for many other structures - Eq. (4) can be used to find the number of cycles, $N_{f}$, for a crack growing from an initial depth $a_{0}$ to a final or critical semi-length $a_{f}$ :

$N_{f}=\int_{a_{0}}^{a_{f}} \frac{\sum_{k} n_{k}}{\sum_{k}\left(\frac{\mathrm{d} a}{\mathrm{~d} N}\right)_{k} \cdot n_{k}} \mathrm{~d} a$

The crack growth rate for block $k,(\mathrm{~d} a / \mathrm{d} N)_{k}$, is determined using Eq. (2) for $\Delta K_{a k}$. Eq. (4) is evaluated with an incremental numerical procedure.

The limit state function for failure associated with the attainment of a crack with a final semi-length $a_{f}$ can be formulated as:

$g(X, t)=N_{f}-t \sum_{k} n_{k}$

or, alternatively:

$g(X, t)=a_{f}-a(t)$

where $t$ is the time difference between the assessment year and the construction year. The failure probability is denoted as:

$P_{f}=P[g(X, t) \leqslant 0]$

Eq. (7) can be calculated using Monte Carlo, First Order Reliability Method (FORM), or other suitable techniques.

Probabilistic FM assessments require a significant calculation time - especially if multiple crack locations are to be considered.

Table 1

\begin{tabular}{|c|c|c|c|c|c|c|c|}
\hline $\mathrm{Nr}$. & Variable & Description & Distribution & $\mu^{\mathrm{a}}$ & $\sigma^{\mathrm{a}}$ & $X_{d}^{\mathrm{a}}$ & $\rho^{\mathrm{a}}$ \\
\hline 1 & $m_{1}$ & Slope value of stage 1 & Deterministic & 5.10 & - & 5.10 & - \\
\hline 2 & $m_{2}$ & Slope value of stage 2 & Deterministic & 2.88 & - & 2.88 & - \\
\hline 3 & $\log _{10}\left(A_{1}\right)$ & Paris Law par. of stage 1 & Normal & -17.32 & 0.32 & -16.68 & 0.64 \\
\hline 4 & $\log _{10}\left(A_{2}\right)$ & Paris Law par. of stage $2 \mathrm{~b}$ & Normal & -12.23 & 0.17 & -11.89 & 0.45 \\
\hline 5 & $\Delta K_{0}$ & Threshold value for $\Delta K$ & Lognormal & 140. & 56. & 63. & 0.75 \\
\hline 6 & VA & Variation on Paris law par. during crack growth & Normal & 1.0 & 0.1 & 1.0 & 0. \\
\hline 7 & $a_{o}$ & Initial crack depth & Lognormal & 0.15 & 0.10 & 0.15 & 0. \\
\hline 8 & $a_{o} / c_{o}$ & Initial aspect ratio & Lognormal & 0.62 & 0.25 & 0.62 & 0. \\
\hline 9 & $a_{f}$ & Semi crack length at failure (conservative value) & Deterministic & 100. & - & 100. & - \\
\hline 10 & $a_{d}$ & $\begin{array}{l}\text { Detectable semi crack length (visual) } \\
\text { or crack depth (ACFM) }\end{array}$ & Weibull & Section 4.4 & - & & $\begin{array}{l}0.70 \\
0.30\end{array}$ \\
\hline 11 & $T$ & Plate thickness & Uniform & 6. & $0.03 \mu$ & 6. & 0. \\
\hline 12 & $L$ & Node length & Uniform & 23. & $0.09 \mu$ & 23. & 0. \\
\hline 13 & $\Delta s$ & Best guess stress ranges ${ }^{c}$ & Deterministic & Fig. 11 & - & & - \\
\hline 14 & $\delta$ & Dynamic amplification factor & Normal & 1.0 & 0.1 & 1.1 & 0. \\
\hline 15 & C & Model uncertainty & Lognormal & 1.0 & 0.27 & 1.0 & 0.85 \\
\hline
\end{tabular}

Probability density functions and design values for random variables (units: $\mathrm{mm}, \mathrm{N}$ ).

a $\mu=$ Average value, $\sigma=$ standard deviation, $X_{d}=$ design value, $\rho=$ spatial correlation coefficient.

b Stress ratio $R=s_{\min } / s_{\max } \geqslant 0.5$, relevant for welded joints, in air conditions.

${ }^{c}$ In agreement with finite element calculations, the membrane and bending portions of the stress range are $40 \%$ and $60 \%$, respectively. 
In order to reduce the calculation time, many studies in the past have considered one stress block only, i.e. using an equivalent load instead of the full variable amplitude load histogram $(k=1)$. Although a division in load blocks is a suitable technique, a too low number of load blocks can result in unsafe predictions of the failure probability after inspection. In order to demonstrate this, Fig. 7 gives the results of a FM calculation using the model and variables described above, for an - arbitrarily selected - variable amplitude and a constant amplitude load. If the variable amplitude load contains a large number of cycles, the crack tends to grow more progressively than in the case of a constant amplitude load, as demonstrated in Fig. 7b. This is caused by the fact that at the initial small crack only the largest stress cycles of the variable amplitude load give a stress intensity range above the threshold. On the contrary almost all stress ranges contribute to the crack growth later in the process when large cracks are present. In case of an arbitrarily selected - detected crack depth $a_{d}=0.5 \mathrm{~mm}$, the figure shows that the remaining life after detection relative to the total life is 0.4 in case of constant amplitude loading while it is only 0.2 in case of the variable amplitude load.

The minimum number of blocks still giving a reasonably accurate prediction of the failure probability after inspection depends on characteristics of the variable amplitude load histogram and should be determined by trial and error for a certain load.

\subsection{Variation on the crack growth velocity within one sample}

Crack growth tests have indicated that the crack growth rate represented by variables $A_{1}$ and $A_{2}$ in Eq. (2) - not only varies between tests but also within a test, especially in case of welded joints. This is caused by aspects such as a varying residual stress over the thickness of the welded joint and variation of grain sizes in the heat affected zone. It is important to incorporate this into the model because the average crack growth rate after the inspection may be different from the one before. A simple manner to incorporate this in the crack growth procedure is applying the Ferry Borges-Castanheta (FBC) process, as proposed for many applications in the JCSS probabilistic model code [33]. The FBC process is generated by a sequence of independent identically distributed random variables, each acting over a given (deterministic) time interval. This is shown in Fig. 8, where the total crack growth process is made up of $r=1$. $n_{r}$ repetitions with:

$$
\begin{aligned}
& A_{1 r}=V A_{r} A_{1} \\
& A_{2 r}=V A_{r} A_{2}
\end{aligned}
$$

where $V A_{r}$ is a measure for the variation in crack growth rate within a sample. The crack growth variables $A_{1}$ and $A_{2}$ in Eq. (2) are replaced by $A_{1 r}$ and $A_{2 r}$, respectively, where $A_{1 r}$ and $A_{2 r}$ act at crack size $a_{r}$, where:

$$
\left(a_{0}+\left[a_{f}-a_{0}\right] \frac{r-1}{n_{r}}\right) \leqslant a_{r}<\left(a_{0}+\left[a_{f}-a_{0}\right] \frac{r}{n_{r}}\right)
$$

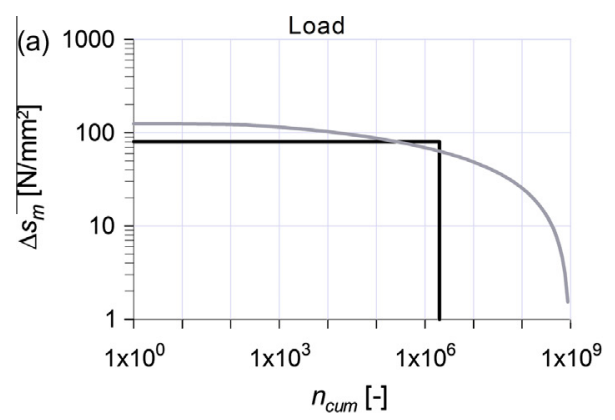

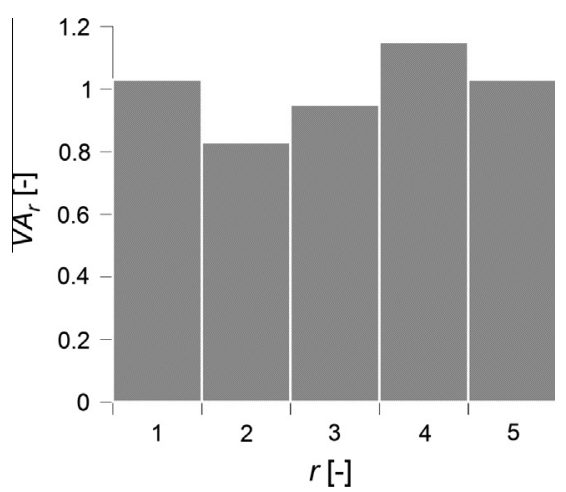

Fig. 8. Schematic representation of the FBC process.

Hence, the FBC process is a rectangular pulse process with changes in amplitude occurring at equal intervals. For the crack growth model used in this paper, $n_{r}=5$ is applied.

\subsection{Probabilistic crack growth model updated with inspection results - one location}

The results of a previous inspection can be considered in the calculation of the failure probability of a detail at a certain location. The following assumptions are applied:

- A detected crack will be immediately repaired.

- The fatigue life of the repaired detail will be sufficient, i.e. larger than the intended life.

The assumptions impose that the locations where a crack has not been detected determine the failure probability. The conditional failure probability at time $t_{2}$ given that a crack was not observed during the inspection at time $t_{1}$ is equal to:

$$
\begin{aligned}
P_{f} & =P\left[g(X, t 2) \leqslant 0 \mid \text { no crack detected at } t_{1}\right] \\
& =P\left(a_{t 2} \geqslant a_{f} \mid a_{t 1}<a_{d}\right)
\end{aligned}
$$

where $a_{t 1}$ and $a_{t 2}$ are the semi crack lengths at times $t_{1}$ and $t_{2}$, respectively, where $t_{2} \geqslant t_{1}, a_{d}$ is the detectable crack size for location $i$, and $a_{f}$ is the final crack size. Updating of the probability of failure using the inspection result can be performed using well known Bayesian methods. The conditional failure probability can then be determined using a crude Monte Carlo analysis:

$P_{f}=\frac{\sum_{j=1}^{n_{M C}} I\left(a_{t 2 j} \geqslant a_{f} \cap a_{t 1 j}<a_{d j}\right)}{\sum_{j=1}^{n_{M C}} I\left(a_{t 1 j}<a_{d j}\right)}$

where $j$ is the Monte Carlo run number and $n_{M C}$ is the total number of Monte Carlo runs in the calculation. $I$ is a logical operator with the following definition:

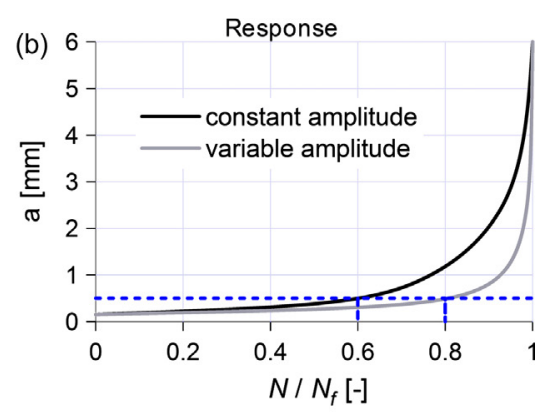

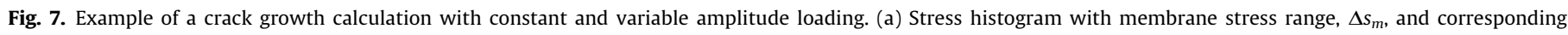
cumulative number of cycles $n_{\text {cum }}$. (b) Resulting crack development with crack depth, $a$, as a function of the fraction of the total fatigue life, $N / N_{f}$. 
$I(A)= \begin{cases}1 & \text { if } A=\text { true } \\ 0 & \text { if } A=\text { false }\end{cases}$

\subsection{Probabilistic crack growth model updated with inspection results - multiple locations}

Evaluation of the failure probability of a system consisting of multiple repetitions of a certain detail depends on the type of system. If the system is a pure series system or a pure parallel system, failure of the system is associated with failure of the first or last of all locations in time, respectively. Structural collapse of a redundant system generally occurs after failure of a number of locations in a row, where each subsequent failure of a location may cause an increase of the stress at the remaining locations. This is a mixture of a series and a parallel system.

In the case of detail S.4.2 of Fig. 5b - occurring twice at every stringer-to-crossbeam joint in a bridge deck - a large crack at one of the locations may generate significant deformations at the deck level, which in turn may cause a traffic accident. Collapse of the entire bridge, however, is extremely unlikely even when multiple locations have cracked. Cracks have to be extremely large before influencing the stress magnitude at other locations. Thus, although various methods are described in literature that consider the influence of cracks on the stress magnitude of neighbouring locations in a probabilistic FM model - $[22,25,34]$ - this has not been considered in the current study. A special case of a series system applies if it is considered that a crack at one of the locations may cause a traffic accident. In this case, it is not important at which location the crack occurs, because the vehicle crossing the bridge passes all locations. Pure parallel systems almost never occur in these structures. Therefore, in the following, the failure probability is evaluated for failure of the 1st of all locations (series system), as well as failure of each individual location.

In case of the series system the conditional failure probability can again be determined using Bayesian methods. The conditional failure probability, $P_{f_{s}}$, is the number of Monte Carlo runs for which the number of cracks at the time of inspection agrees with the inspection result and for which at least one non-detected crack at the time of inspection has reached the critical size before the end of the required life, divided by the total number of runs for which the number of cracks at the time of inspection agrees with the inspection result:

$P_{f s}=\frac{\sum_{j=1}^{n_{M C}} I\left[\bigcup_{i=1}^{n_{\text {loc }}}\left(a_{t 2 i j} \geqslant a_{f} \wedge a_{t 1 i j} \leqslant a_{d i j}\right) \cap\left(\sum_{i=1}^{n_{\text {loc }} I} I\left(a_{t 1 i j}>a_{d i j}\right)\right)=n_{d t 1}\right]}{\sum_{j=1}^{n_{M C}} I\left[\left(\sum_{i=1}^{n_{l o c}} I\left(a_{t 1 i j}>a_{d i j}\right)\right)=n_{d t 1}\right]}$

where $n_{d t 1}$ is the number of detected cracks at the time of inspection, $t_{1}, i$ is the location considered and $n_{l o c}$ is the total number of locations - or repetitions - of the type of detail in the bridge. The failure probability per location, $P_{f}$, is obtained by:

$P_{f i}=\frac{\sum_{j=1}^{n_{M C}} \sum_{i=1}^{n_{\text {loc }}} I\left[a_{t 2 i j} \geqslant a_{f} \wedge a_{t 1 i j} \leqslant a_{d i j}\right] \cdot I\left[\left(\sum_{i=1}^{n_{\text {loc }}} I\left(a_{t 1 i j}>a_{d i j}\right)\right)=n_{d t 1}\right]}{\sum_{j=1}^{n_{M C}}\left(n-n_{d t 1}\right) I\left[\left(\sum_{i=1}^{n_{\text {loc }} I} I\left(a_{t 1 i j}>a_{d i j}\right)\right)=n_{d t 1}\right]}$

The reliability of a structure is usually expressed with the reliability index. The reliability of the whole period, $\beta$, is related to the failure probability as follows:

$\beta=-\Phi\left(P_{f}\right)$

where $\Phi$ is the cumulative distribution function of the standard normal distribution.
Note that Eqs. (13) and (14) are again based on the assumptions that a detected crack is repaired and that the fatigue life of the repaired detail is sufficient. Eqs. (13) and (14) can easily be extended to the case with more than one inspection in time.

\subsection{Correlation coefficients}

In case a detail type is considered that occurs multiple times in a structure, spatial correlations may be taken into account. The spatial correlations origin from the fact that bridge deck is constructed out of one steel grade by one company, using the same welding procedures and quality standards for all locations. In addition the details are subjected to equal or similar loading events. The spatial correlations of all random variables are considered in the probabilistic FM model.

The spatial correlation coefficient of variable $x$ is determined via the following procedure:

1. The coefficient of variation for the entire distribution is determined for each random variable $x$ :

$V_{\text {tot }}(x)=\frac{\sigma_{\text {tot }}(x)}{\mu(x)}$

where $V_{\text {tot }}$ is the coefficient of variation of the entire distribution of variable $x, \sigma_{\text {tot }}(x)$ is the standard deviation of the entire distribution of variable $x$, and $\mu(x)$ is the expectation of variable $x$.

2 . For the same variable $x$, the variation between the potential crack locations of a certain detail within one structure, $V_{d e p}(x)$, is determined:

$V_{\text {dep }}(x)=\frac{\sigma_{d e p}(x)}{\mu(x)}$

where $V_{d e p}(x)$ and $\sigma_{d e p}(x)$ are the coefficient of variation and the standard deviation of the distribution of $x$ within one structure.

3. In case $x$ is normal distributed, the correlation coefficient, $\rho(x)$, follows from:

$\rho(x)=1-\frac{V_{d e p}^{2}(x)}{V_{\text {tot }}^{2}(x)}$

A variable $x$ that is not normally distributed can be transformed into a standard normal distributed variable $u$ in such a way that $F(x)=\Phi(u)$,

where $F(x)$ is the cumulative distribution of $x$. Correlation is considered in the Monte Carlo simulations by transformation of the correlated variables into uncorrelated variables using the Rosenblatt transformation, [35]. An alternative to the Rosenblatt method is the generalized Nataf model which is also widely used. These two transformations are fully in line for the normal copula case as is demonstrated in [36]. For standard normal distributed variables the Rosenblatt transformation reads:

$$
\begin{aligned}
& F\left(u_{1}\right)=\Phi\left(u_{1}\right) \\
& F\left(u_{2} \mid u_{1}\right)=\Phi\left(\frac{u_{2}+\frac{\zeta_{12}^{(2)}}{\xi_{22}^{(2)}} u_{1}}{\sqrt{\operatorname{det} \rho^{(2)}} / \zeta_{22}^{(2)}}\right) \\
& \ldots \\
& F\left(u_{n_{l o c}} \mid u_{n_{l o c}-1}, \ldots u_{1}\right)=\Phi\left(\frac{u_{n_{l o c}}+\sum_{r=1}^{n_{l o c}-1} \frac{\zeta m_{l o c}}{\zeta n_{l o c} n_{l o c}} u_{r}}{\sqrt{\operatorname{det} \rho} / \zeta_{n_{l o c} n_{l o c}}}\right)
\end{aligned}
$$

where $\rho$ is the correlation matrix, $\rho^{(r)}$ is the correlation matrix of variables (locations) $1 \ldots r$, and $\zeta^{(r)}$ st is the cofactor of correlation $\boldsymbol{\rho}_{s t}$ in $\boldsymbol{\rho}^{(r)}$. The transformation is easily obtained using the eigenvalues, $\boldsymbol{\Lambda}$, and eigenvectors, $\boldsymbol{W}$, of the correlation matrix, $\boldsymbol{\rho}$ [37]: 


$$
\boldsymbol{\rho}=\boldsymbol{W}^{T} \boldsymbol{\Lambda} \boldsymbol{W}
$$

Average values, standard deviations and correlation coefficients for each random variable are provided in the following section.

\section{Distributions of the variables}

\subsection{Crack growth variables}

The crack growth variables $m_{1}, m_{2}, A_{1}, A_{2}$ and $\Delta K_{0}$ are random variables and a strong correlation exist between $m$ and $A$. Some studies state that this correlation is just a consequence of the mathematical description of the Paris law, [38,39], while others indicate that there is a physical relationship [40]. For one material, the scatter in $m$ is very small. The British standard BS 7910:2013 [28] uses fixed values for $m_{1}$ and $m_{2}$, and all scatter in crack growth is incorporated in the distributions of $A_{1}$ and $A_{2}$. Here, the same reasoning is followed and lognormal distributions with parameters according to Table 1 have been incorporated in agreement with that standard. The resulting coefficients of variation for $A_{1}$ and $A_{2}$ are $V_{\text {tot }}=1.7$ and $V_{\text {tot }}=0.6$, respectively. The distribution of $\Delta K_{0}$ is obtained from [41], resulting in a coefficient of variation equal to $V_{\text {tot }}=0.4$.

The variation of the crack growth rate within one experiment, modelled by the FBC process as indicated in Section 3.2, is obtained by evaluating measured crack growth rates in tests. The variations resulting from crack growth tests are not only due to physical variations but also due to inherent inaccuracies in the measurement of the crack growth rate. For this reason, information on the variation of the crack growth rate within one sample is based on test series where the crack growth rate is measured with great accuracy. Two test series carried out on welded steels in the laboratories of Eindhoven University of Technology and TNO, [42,43], have been reanalysed for this purpose (Fig. 9). In addition, tests reported in [44] have been considered. Based on this information, the coefficient of variation of $V A$ is determined at 0.1 .

The information from [42,43] (Fig. 9) has also been used to determine the correlation $\rho$ of variable $A_{2}$ between different samples of the same series. The coefficient of variation for the series in $[42,43]$ is equal to $V_{\text {dep }}=0.2$. However, this coefficient of variation is based on samples taken from one base material plate and welded by one person. A structure such as a bridge deck is usually constructed by one company, with certain quality standards and welding procedures, and using material from one steel supplier, but often more than one welder is involved and the deck is constructed from base material plates possibly not originating from the same batch. The test data reported in [44] have been determined from welded joints constructed from different steel grades and different welding processes. The coefficient of variation for $A_{2}$ based on all tests in [44] is equal to $V_{d e p}=0.2$. However, the number of tests in [44] is limited and therefore the value 0.2 is uncertain. A somewhat higher value of $V_{d e p}=0.3$ is considered as a reasonable to conservative assumption in this study. As provided above the coefficient of variation of the entire distribution is $V_{\text {tot }}=0.6$. Using the procedure outlined in Section 3.5, the correlation coefficient for $\log _{10}\left(A_{2}\right)$ is determined at $\rho=0.64$.

The information in [44] is also used to determine the coefficients of variation for variables $A_{1}$ and $\Delta K_{0}$. These coefficients of variation are 0.4 and smaller than 0.1 , respectively. Because these values are based on limited test data, the coefficients of variation considered in this study are conservatively taken as $V_{d e p}=1.0$ and $V_{d e p}=0.2$, respectively. The coefficients of variations for the entire distribution are $V_{\text {tot }}=1.7$ and $V_{\text {tot }}=0.4$, respectively, so that the resulting correlation coefficients for $\log _{10}\left(A_{1}\right)$ and $\Delta K_{0}$ are $\rho=0.45$ and $\rho=0.75$, respectively. A future, more extensive survey may provide more accurate values for $V_{d e p}$ of all crack growth variables, which may remove conservatism.

\subsection{Initial flaw size}

An equivalent initial flaw size distribution should be considered for use in a FM assessment, [45]. The distributions for $a_{0}$ and $a_{0} / c_{0}$ in Table 1 are obtained from [46,47], resulting in $V_{\text {tot }}=0.66$ and $V_{\text {tot }}=0.40$, respectively. It is difficult to directly determine the correlation coefficients for $a_{0}$ and $a_{0} / c_{0}$ due to lack of accurate data. For this reason, the correlation coefficients are determined indirectly, by comparing the FM prediction with the number of cycles to failure following from tests. A cruciform welded joint is considered for this comparison because the analytical expressions for the SIF are well defined and evaluated for this type of joint. The data in [48] (Fig. 10) is used for the comparison, because a complete overview of well-defined and well-documented test campaigns carried out with different welding processes is provided there. In order to exclude the effect of different thicknesses the data plotted in Fig. 10 are normalised to a plate thickness of $25 \mathrm{~mm}$ using the relationship:

$\Delta s^{\prime}=\Delta s\left(\frac{25 \mathrm{~mm}}{T}\right)^{0.2}$

where $\Delta s^{\prime}$ is the normalised stress range for a plate thickness of $25 \mathrm{~mm}, \Delta s$ is the stress range applied in the test and $T$ is the plate thickness. Eq. (18) is provided in many standards on fatigue of cruciform joints and it agrees well with the results of FM calculations. The coefficient of variation is determined for all series together using the corrected stress ranges $\Delta s^{\prime}$. This has resulted in a standard deviation of $\log _{10}(D)$ equal to 0.26 , where $D$ is defined as:

$D=\Delta s^{3} N_{f}$
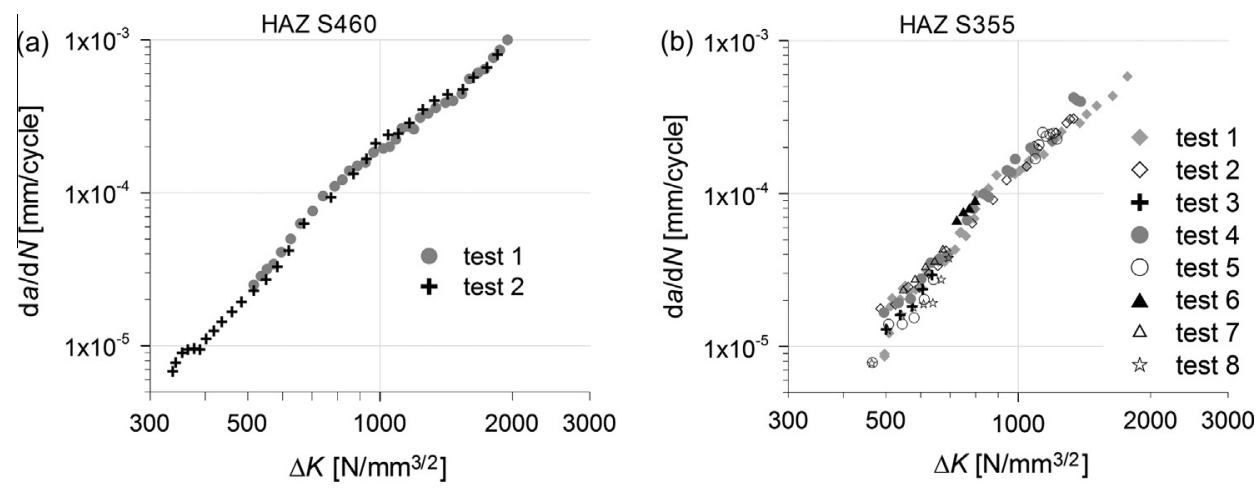

Fig. 9. Crack growth relationships measured in test campaigns on welded specimens. (a) Data for S460 [43]. (b) Data for S355 [44]. 


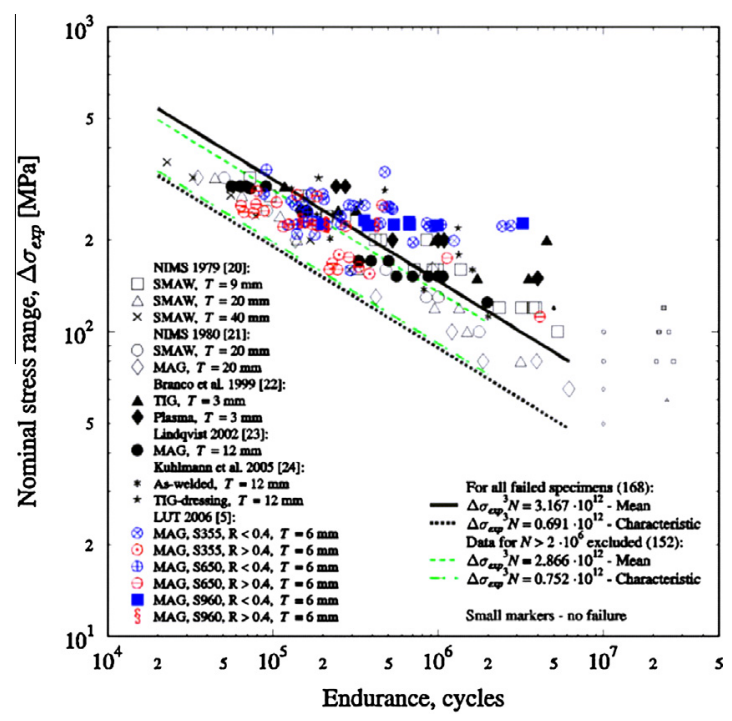

Fig. 10. Test results (S-N data) on cruciform joints determined in well-defined test campaigns (reprinted from [49]).

Probabilistic FM calculations have been carried out for cruciform joints in this study, using the distributions of random variables in Table 1 (variables $1-8,11$ and 12 , but with adapted average values for variables 11 and 12). The resulting standard deviation of $\log _{10}(D)$ of these calculations was equal to 0.25 . Hence, a good agreement exists between the tests and the FM calculations regarding the coefficient of variation of $D$.

The test series in [48] (Fig. 10) have then been considered individually. The average standard deviation of $\log _{10}(D)$ of the individual test series is equal to 0.16 . FM calculation using the variations $V_{\text {dep }}$ of all crack growth variables, in combination with the coefficients of variation $V_{\text {tot }}$ for the initial flaw dimensions, results in a standard deviation of $\log _{10}(D)$ equal to 0.14 . Again, a good agreement exists. For this reason the variations $V_{d e p}$ are set equal to $V_{\text {tot }}$ for $a_{0}$ and $a_{0} / c_{0}$, so that the correlation coefficients for the initial flaw dimensions are $\rho=0$.

\subsection{Final crack length}

Several criteria can be considered for the final crack size, $a_{f}$, such as:

- A critical crack size at which unstable crack growth or fracture occurs.

- A crack size at which the deformation is such that the safety of users is jeopardised.

Regarding the first criteria, structures such as bridge decks or ship decks are in general relatively tolerant to large cracks. This is due to the combination of the following aspects:

- These structures are typically constructed from mild steels (nominal yield strength up to $355 \mathrm{~N} / \mathrm{mm}^{2}$ ) that comply with minimum toughness requirements put forward in steel quality standards. This result in relatively tough steels.

- Multiple load paths are present, resulting in load shedding effects for large cracks and relatively redundant structures.

- Many of the welded details are predominantly loaded by imposed deformation. The deformation restraint reduces when the crack advances in length, so that the crack driving force reduces at increasing crack length.
- The external load is often a compressive load. (The positive stress ratio $R=s_{\max } / s_{\min }$ that drives the fatigue crack growth results from residual welding stresses.)

Tests on orthotropic bridge decks are summarised in Kolstein [49]. Unstable crack growth or fracture was not demonstrated in any of the full scale tests in [49], even though the crack sizes at the end of testing were often large $(>200 \mathrm{~mm}$ ) and load levels were higher than what may be expected in practice.

Determination of the final crack size is relatively straightforward when using the finite element method in combination with a failure assessment diagram (critical crack) or a deformation criterion. The subsequent incorporation of the final crack criterion into the probabilistic framework is also possible as demonstrated in [50]. Assessment of the final crack size is beyond the scope of this paper. Instead a deterministic value of $a_{f}=100 \mathrm{~mm}$ (through-thickness crack) is considered here, which is expected to be a conservative value for crack type S.4.2.

\subsection{Detectable crack size}

Visual inspections by the naked eye - i.e. excluding dye penetrant and magnetic particle inspections - are often excluded in overviews of Probability of Detection (POD) curves such as [51]. This is due to individual inspector differences being are a major factor in the quality and reliability of visual inspections, [52,53]. In addition small cracks cannot be detected with sufficient reliability using visual inspection. However, fatigue inspections usually aim at detecting a single crack with a relatively small size - often a crack that has not yet grown through thickness. In the current study, a detail is considered that occurs multiple times in the structure, and the structure is tolerant to relatively large cracks.

The PoD of an inspection technique depends on the type of detail, the accessibility of the detail and the skills of the inspector. General information about the PoD curve for detecting throughthickness cracks by visual inspections is available in [54,55] which is summarised and applied in [56]. A Weibull distribution is assumed for the PoD in [56]:

$P o D=1-\exp \left[-\left(\frac{a_{d}-a^{*}}{\lambda-a^{*}}\right)^{\alpha}\right]$

where $a_{d}$ is the detectable through-thickness semi crack length of the visual inspection, $\alpha=0.5$ and $a^{*}$ and $\lambda$ depend on the accessibility (Table 2). The accessibility of crack S.4.2 is estimated as between 'good' and 'difficult', depending on the type of bridge structure and the access facilities such as inspection paths below the bridge.

For reasons of comparison, inspections with the alternating current field method (ACFM) are also considered in this paper. This more accurate inspection method is able to detect surface cracks and the PoD curve is better known. The PoD of ACFM reported in [57] is curve-fitted with the Weibull distribution according to Eq. (23), where $a_{d}$ is the detectable crack depth of the surface crack, $\alpha=0.8, a^{*}=0.8 \mathrm{~mm}$ and $\lambda=1.12 \mathrm{~mm}$. The PoD of the considered inspection methods are provided in Fig. 11. A relatively high correlation coefficient of $\rho=0.7$ is assumed for the visual inspection in order to account for the significant influence of the skills of the inspector. The ACFM inspection is less depending on the operator skills and a correlation coefficient of $\rho=0.3$ is assumed.

\subsection{Geometry}

The governing dimensions in the expressions of the correction factors, $Y$ and $M$, are the crack size parameters, $a$ and $c$, the plate thickness of the stringer, $T$, and the node length, $L$. According to [33] a uniform distribution may be assumed for $T$, with a 
Table 2

Weibull parameters $a^{*}$ and $\lambda$ in Eq. (23) for visual inspection.

\begin{tabular}{llclll}
\hline Accessibility & Excellent & Good & Fair & Not easy & Difficult \\
\hline$a^{*}(\mathrm{~mm})$ & 2.5 & 5 & 10 & 15 & 20 \\
$\lambda(\mathrm{mm})$ & 5 & 10 & 20 & 30 & 40
\end{tabular}

coefficient of variation of $V_{\text {tot }}=0.03$. The scatter in the node length $L$ is a function of the scatter in the thickness of the crossbeam and the scatter in the weld throat. A uniform distribution is assumed for the weld throat with a coefficient of variation of $V_{\text {tot }}=0.15$. The average dimensions in Table 1 are common values for detail S.4.2 in existing bridges in Europe. In case of a bridge with a large span, plates originating from more than one material batch are used. Therefore, spatial correlation has not been considered and $\rho=0$.

\subsection{Best guess stress ranges and numbers of cycles}

Two types of stress histogram are considered, with annual stress range distributions according to the Weibull function:

$n_{k}=n_{\text {tot }}\left(\frac{q}{u}\left(\frac{\Delta s_{k}}{u}\right)^{q-1} \exp \left[-\left(\frac{\Delta s_{k}}{u}\right)^{q}\right]\right)$

where $n_{k}$ is the annual number of cycles with expected stress range $\Delta s_{k}$. Parameters $n_{\text {tot }}, u$ and $q$ are provided in Table 3. The shape parameters, $q$, are selected in agreement with traffic load measurements in the Netherlands, [58]. Based on the same measurements, the total annual number of cycles, $n_{\text {tot }}$, in histogram 1 is representative for the number of axles of heavy vehicles passing a motorway bridge. The total number of cycles in histogram 2 is a factor of 10 lower and this could represent a bridge in a local road. Due to the different number of cycles, the deck structure of the two bridge decks may have different dimensions, resulting in different stress ranges. The scale parameters, $u$, for both histograms are selected in such a way that a first inspection is required after approximately 25 years in service. The most important difference between histograms 1 and 2 is that the number of samples in histogram 1 with infinite life (i.e. $\Delta K$ calculated at the initial crack size and the maximum stress range is smaller than $\Delta K_{0}$ ) is one order of magnitude larger than for histogram 2.

The resulting stress histograms are divided into a number of blocks with constant amplitude, Fig. 12. Preliminary calculations have indicated that the error in the failure probability is less than $3 \%$ when using this block load approximation.

The stress ranges of Fig. 12 are based on traffic measurements, including dynamics of vehicles but excluding a dynamic interaction effect between the vehicles and the bridge. A dynamic interaction effect should therefore be taken into account and for bridges it is usual to consider this by an amplification factor for the stress
Table 3

Parameters of the Weibull function for annual stress range distributions in Eq. (24)

\begin{tabular}{llll}
\hline Case & $n_{\text {tot }}\left(\right.$ year $\left.^{-1}\right)$ & $q(-)$ & $u\left(\mathrm{~N} / \mathrm{mm}^{2}\right)$ \\
\hline Histogram 1 & $8.10^{6}$ & 1.9 & 19 \\
Histogram 2 & $8.10^{5}$ & 1.4 & 22
\end{tabular}

ranges, $\delta$, Eq. (3). A theoretical analysis has indicated that $\delta$ is small for fatigue of bridge decks, [59]. The expectation of the factor considered in this study is 1.0 and the coefficient of variation is $V_{\text {tot }}=0.1$. Spatial correlation is not expected: $\rho=0$.

\subsection{Uncertainties}

A number of uncertainties need to be considered. The JCCS probabilistic model code, [33], recommends lognormal distributed aspect uncertainty factors, all having an expectation of 1 :

- An uncertainty factor for the fluctuating load model, $C_{\text {load, }}$, accounting for uncertainty in the axle loads. The load model for bridges is generally based on traffic load measurements and is expected to be reasonably accurate. A coefficient of variation of $V_{\text {tot }}=0.1$ is assumed. Because the vehicles cross the entire bridge, there exists full spatial correlation between the potential crack locations, $\rho=1$. Correlation not only exists in space but also in time. Several possibilities exist to model variation in time, amongst others the FBC process of Section 3.2. In this paper, first a constant value for $C_{\text {load }}$ is considered during

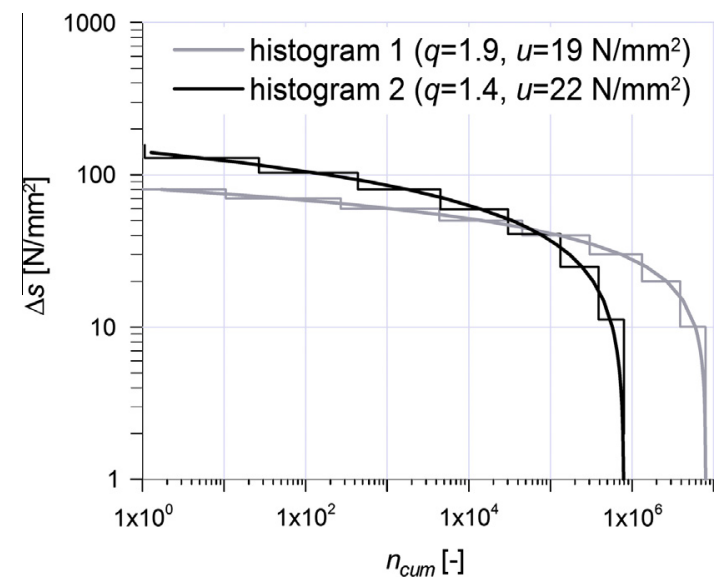

Fig. 12. Stress histograms, with expected stress range, $E(\Delta s)$, versus cumulative annual number of cycles, $n_{\text {cum }}$.

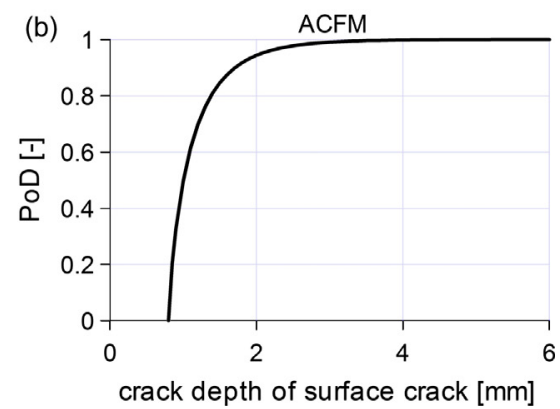

Fig. 11. Probability of detection (PoD) of inspection methods. (a) Visual inspection. (b) ACFM inspection. 
the entire crack growth process, which corresponds to full correlation in time. Subsequently the FBC process is applied with a coefficient of variation $V_{\text {tot }}=0.1$.

- An uncertainty factor for the stress model, $C_{F E M}$, accounting for the inaccuracies of the finite element model of the bridge deck structure. The coefficient of variation recommended in [33] is $V_{\text {tot }}=0.1$. There exists full spatial correlation between the potential crack locations, $\rho=1$.

- An uncertainty factor $C_{M}$ accounting for inaccuracies in the parametric description of the geometric correction factors, $Y$ and $M$. The coefficient of variation recommended in [33] is $V_{\text {tot }}=0.2$. Because the details are equal, there exists full spatial correlation between the potential crack locations, $\rho=1$.

- The stresses in a bridge deck depend on the stiffness and thickness of the (asphalt) surface finish. This stiffness and thickness introduces an additional uncertainty, which is not yet covered by the previous uncertainty factors. An additional model uncertainty factor $C_{s f}$ is therefore introduced for which a variation of 0.1 is assumed. It is assumed that $\rho=0$ although this may be a conservative estimation. A further study may provide a quantified, less conservative value for this correlation coefficient.

The total uncertainty factor, $C$, is a multiplication of all four aspect uncertainty factors:

$C=C_{\text {load }} C_{F E M} C_{M} C_{s f}$

The resulting variable $C$ has a lognormal distribution with expectation of $1, V_{\text {tot }}=0.27$ and $\rho_{c}=0.85$.

\section{Results and discussion}

Fig. 13 presents the evolution of the reliability index for the whole period per location, $\beta_{i}$ according to Eqs. (13) and (15), as a function of time, for the two stress histograms of Fig. 12 and the distributions of variables and spatial correlations according to Table 1 . The green curve provides the results for a welded structure prior to inspections. Considering a minimum acceptable reliability index for failure per location of $\beta_{a c c}=3.1$ means that a first inspection is required after 25 years in service. The other curves in Fig. 13 are for visual inspection with 'good accessibility' (PoD curve in Fig. 11a) and where $n_{d t 1}=0$, i.e. cracks are not detected. The inspection results in an instant increase and a subsequent gradual decrease of $\beta_{i}$ and finally the curve after inspection approaches the original curve. The figure clearly demonstrates the significance of the spatial correlations, as the curve for $n_{\text {loc }}=100$ (i.e. 100 locations considered in the calculation) is well above the curve for $n_{l o c}=1$. Had correlations not been considered, the curves would have been equal. Using the criterion of $\beta_{a c c}=3.1$, the required intervals between the first and second inspection are presented in Table 4. The significant differences between 1 and 100 locations for all cases considered emphasizes the importance of considering spatial correlations between potential crack locations. For the cases considered, a visual inspection with $n_{\text {loc }}=100$ provides a similar inspection interval as an ACFM inspection with $n_{l o c}=1$. The fact that the inspection interval for a visual inspection with $n_{l o c}=1$ is reasonable despite the poor $\mathrm{PoD}$ is attributed to the tolerance to large cracks considered $\left(a_{f}=100 \mathrm{~mm}\right)$.

For all simulations carried out, the results of histograms 1 and 2 are similar from a qualitative point of view. Therefore, only the results of histogram 1 are presented in Figs. 14-16. In all simulations for these figures, 100 locations have been considered. Figures 'a' provide the reliability index corresponding to the 1st failure of all 100 locations, $\beta_{s}$, which is based on Eq. (13) and figures 'b' give the reliability index per location, $\beta_{i}$, based on Eq. (14), both values for the whole period. Fig. 14 demonstrates the influence of the PoD of the inspection technique. Results are presented for the case that $n_{d t 1}=0$. In agreement with the expectation, ACFM provides the largest instant increase in reliability and the largest required inspection interval. The figure also demonstrates that the two PoD curves considered for visual inspection provide a similar update of the reliability. Thus the exact PoD curve of the visual inspection is - within certain limits - not a major factor. This is a consequence of the tolerance to large cracks, of the conservative assumption of a straight fronted crack as soon as the crack is surface breaking (Fig. 4) and of the assumption that only throughthickness cracks can be detected visually: At the attainment of a through-thickness crack, the crack is of such length that it can be detected with reasonable probability even with a visual inspection with the poor PoD curve.

In order to investigate the effect of a partial inspection, a simulation is carried out with the PoD for ACFM and where $10 \%$ of all locations (10 out of 100 ) are inspected. The resulting purple curve is almost on top of the original green curve without inspection, indicating that such an inspection is of little use especially in case of a series system (Fig. 14a).

Fig. 15 provides the results of 1 and 2 visual inspections with "good accessibility" and with $n_{d t 1}=0$. The figure indicates that the required inspection interval after the 2nd inspection is larger than that after the 1 st inspection. Simulations with various

Table 4

Required interval in years between 1 st and 2 nd inspection for the example cases.

\begin{tabular}{lllll}
\hline Case & Visual $^{\mathrm{a}}$, & Visual $^{\mathrm{a}}$, & ACFM, \\
& $n_{\text {loc }}=1$ & $n_{\text {loc }}=100$ & $\begin{array}{l}\text { ACFM, } \\
n_{\text {loc }}=1\end{array}$ & $n_{\text {loc }}=100$ \\
\hline Stress histogram 1 & 16 & 42 & 23 & 61 \\
Stress histogram 2 & 8 & 20 & 17 & 42 \\
\hline
\end{tabular}

a Assuming "good accessibility".
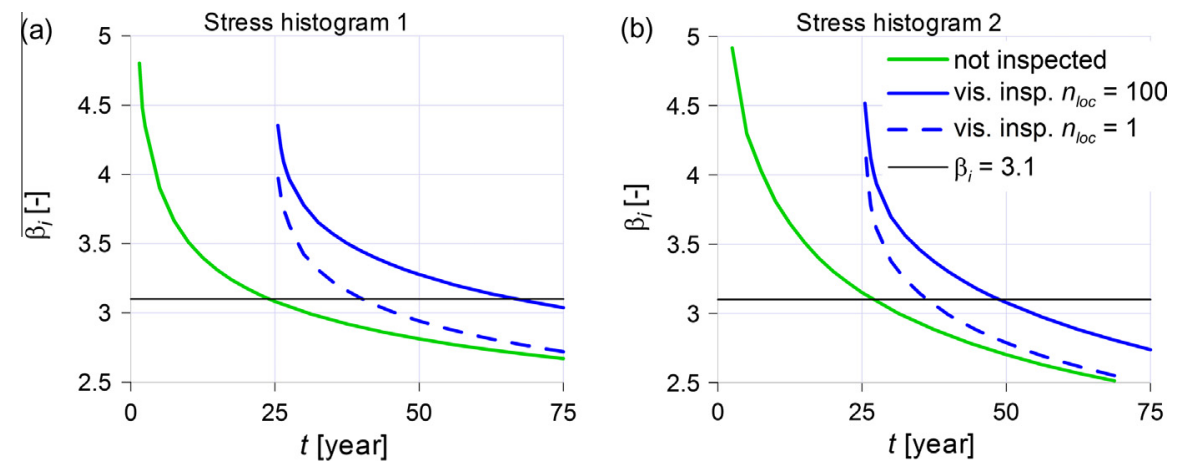

Fig. 13. Reliability index per location in case of visual inspections with a 1 or 100 locations. (a) Stress histogram 1 (Fig. 12 ). (b) Stress histogram 2. 

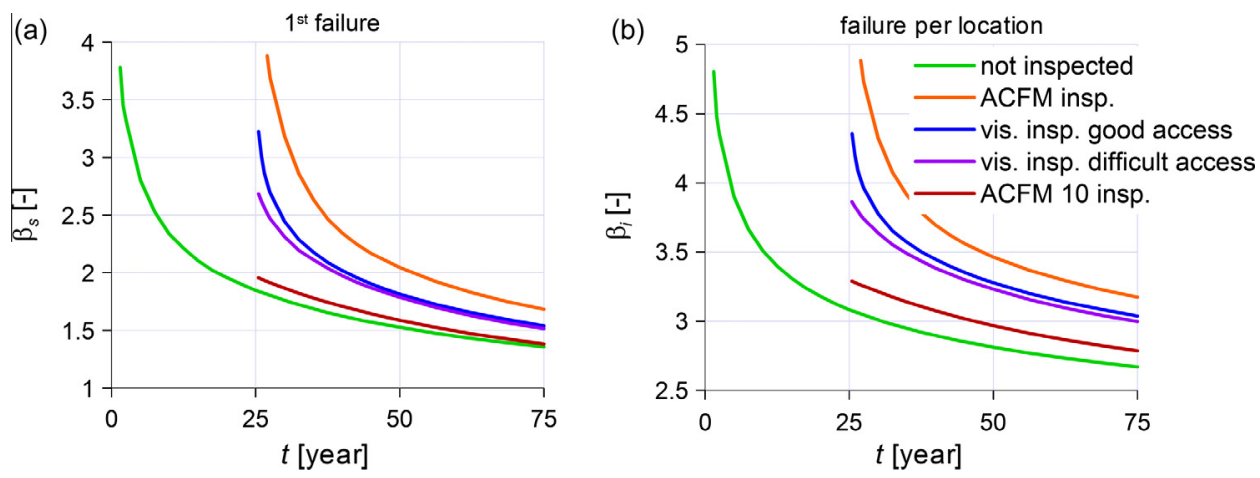

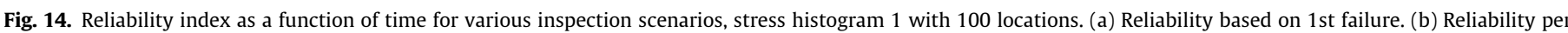
location.
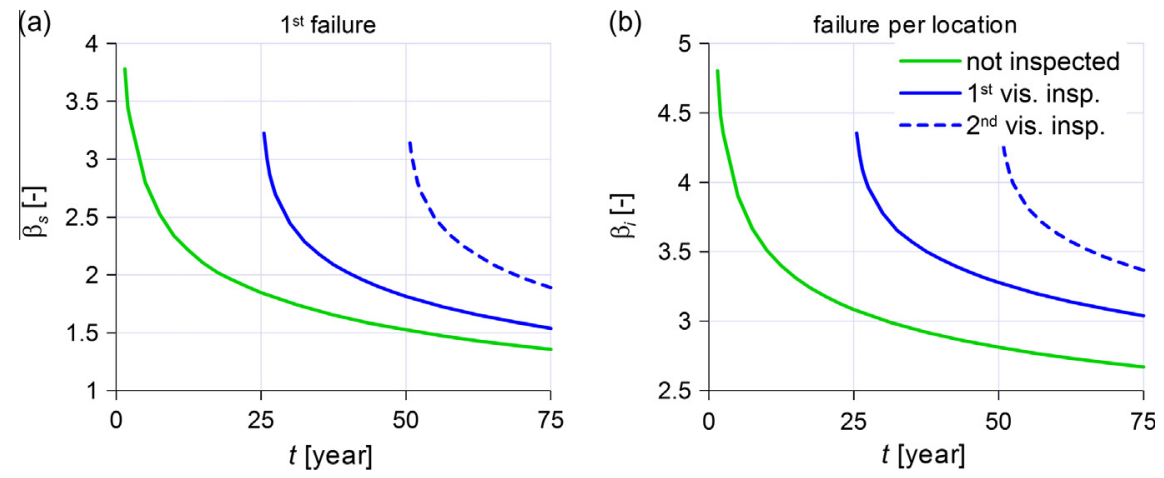


Reliability per location.
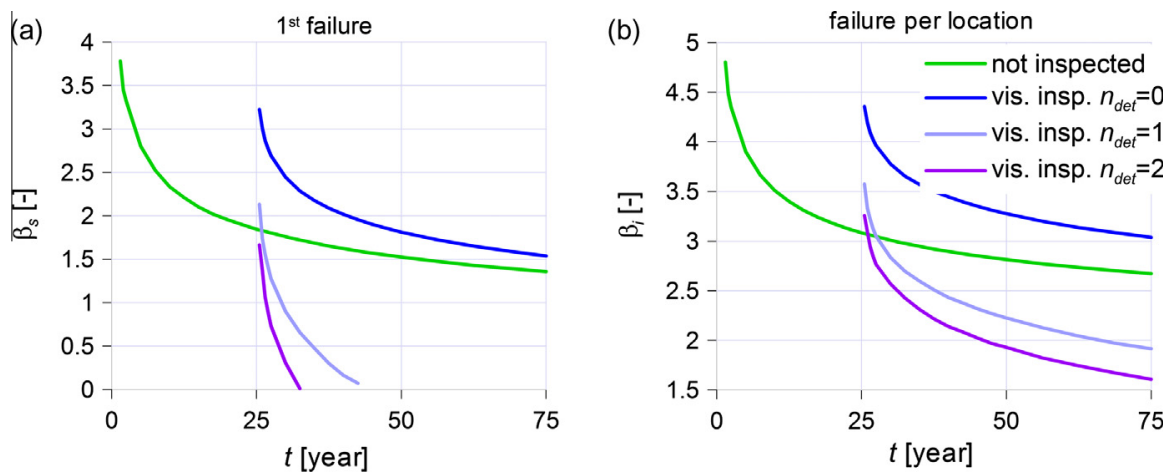

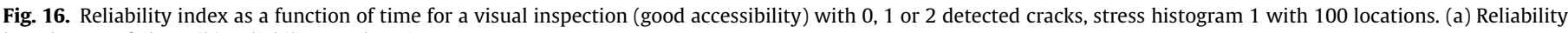
based on 1 st failure. (b) Reliability per location.

inspection scenarios revealed a similar increasing inspection interval in time if cracks are not detected. Other researchers have obtained the same result for simulation of 1 location, e.g. [60]. Intuitively this is in contradiction with the often observed 'bathtub' curve for the probability of fatigue failure in time, where the probability increases as the expected end-of-life approaches. A solution presented in [61] is to consider an increasing number of initiation points in time, but a quantified proposal based on physical evidence has not yet been provided. This is a subject for further study.

Fig. 16 provides the results of a visual inspection with a number of detected cracks, $n_{\text {det }}$, equal to 0,1 or 2 . A substantial drop in reliability is observed for the locations without a detected crack resulting in an extremely short inspection interval - in case one or two cracks out of 100 locations have been detected. In this case the result of the inspection deviates from the initial expectation: the a priori probability of two or more cracks being detected at the $1 \mathrm{st}$ inspection resulting from the calculation is $P\left(n_{\text {det }} \geqslant 2\right)=0.016$. The possibility of false hits (i.e. a detection while a crack is not present) has not been considered in the framework presented in this paper, but is one of the first aspects to be checked. If it is demonstrated that the detections are actual cracks, the model and the prior distributions of Table 1 should be re-evaluated. The updated (posterior) distributions of the variables provide a hint on the variables that should be re-evaluated.

As an example, Fig. 17 presents the distributions of the variables for which a substantial difference was found between the prior and posterior distributions for the case $n_{\text {det }}=2$. The figure provides the posteriors for those locations where cracks have been detected 
$\left(a_{t 1 i}>a_{d i}\right)$ and the posteriors for all locations in the Monte Carlo simulations with $n_{d e t}=2$. For some variables, the posteriors have a wider distribution than the priors $\left(A_{1}, a_{0}\right)$, for some the posterior is narrower $\left(\Delta K_{0}\right)$ and for some variables, the distributions are shifted $\left(C_{t o t}, \delta\right)$. The posteriors for all locations of variables $a_{0}$ and $\delta$ are equal to their priors because the correlation coefficients for these variables were 0 . The figure indicates that the difference between prior and posterior is especially large for variables $A_{1}$ and $C_{\text {tot }}$. This also emphasizes the relative importance of these variables. Variable $C_{\text {tot }}$ largely depends on the case considered, for example $C_{\text {load }}$ may be different for different applications. Hence it is of great importance that the uncertainty factors be well estimated and expert judgement is often required.

The results of Figs. 13-17 are carried out with a fixed uncertainty in time, i.e. variable $C_{\text {load }}$ of Section 4.7 is constant in time. A more realistic case results when considering a varying uncertainty in time. Therefore additional simulations have been carried out considering the FBC process with a coefficient of variation $V=0.1$. Fig. 18 compares the results of the simulations with fixed uncertainty in time (solid curves) with those of varying uncertainty in time (dashed curves). Due to the larger total uncertainty in this case the first inspection needs to be carried out 5 years earlier for the case with varying uncertainty when considering $\beta_{\text {acc }}=3.1$ for both cases. It is obvious that the required time interval to the 2nd inspection also decreases. For stress histogram 1 the ratio between the required time between erection of the bridge and the $1 \mathrm{st}$ inspection and the required time between the $1 \mathrm{st}$ and the 2nd inspection is 1.7 for the case with constant uncertainty and
0.9 for the case with varying uncertainty. On the other hand, a ratio of 0.9 is expected to be well acceptable for bridge managers.

The method presented in this paper requires historical data e.g. with respect to the loads that have been applied since the erection of the structure. For some types of structure such data is unavailable or difficult to obtain. Poor data should be accompanied by a large coefficient of variation of the uncertainty factor in the method presented. In such a case, inspections are essential and inspection results will dominate the updating procedure. Inspection requires details to be accessible. Inaccessible or difficult-toaccess details in fatigue loaded structures are not desirable but some structures have been constructed - and continue to be constructed - with such details. It is evident that the method presented in this paper does not apply to inaccessible details because inspection data are a prerequisite. In view of the authors, such details should be designed according to the safe life fatigue verification method and it should be taken care of that (fatigue) cracks in such details do not result in a catastrophic failure of the entire structure.

\section{Conclusions and recommendations}

This paper presents a probabilistic model for a crack growth (fracture mechanics) analysis in which the results of inspections are considered. Contrary to studies carried out by others, this paper considers the spatial correlations of all variables if fatigue sensitive details occur multiple times in structures. The model is
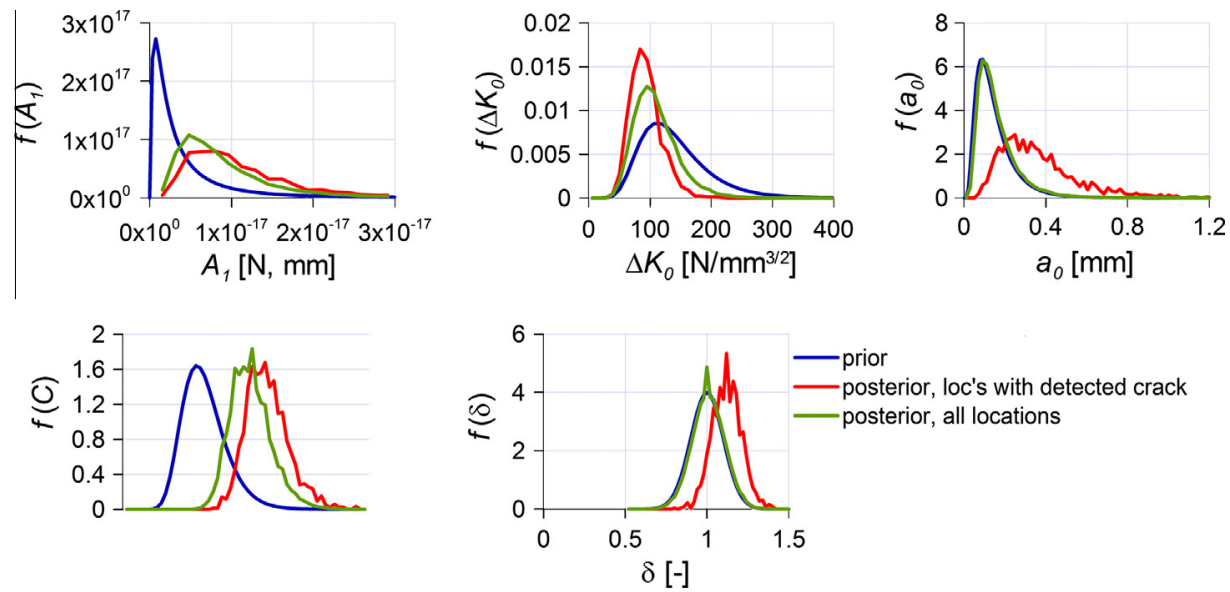

Fig. 17. Prior and posterior distributions of important variables for a visual inspection with 2 detected cracks, stress histogram 1 with 100 locations.
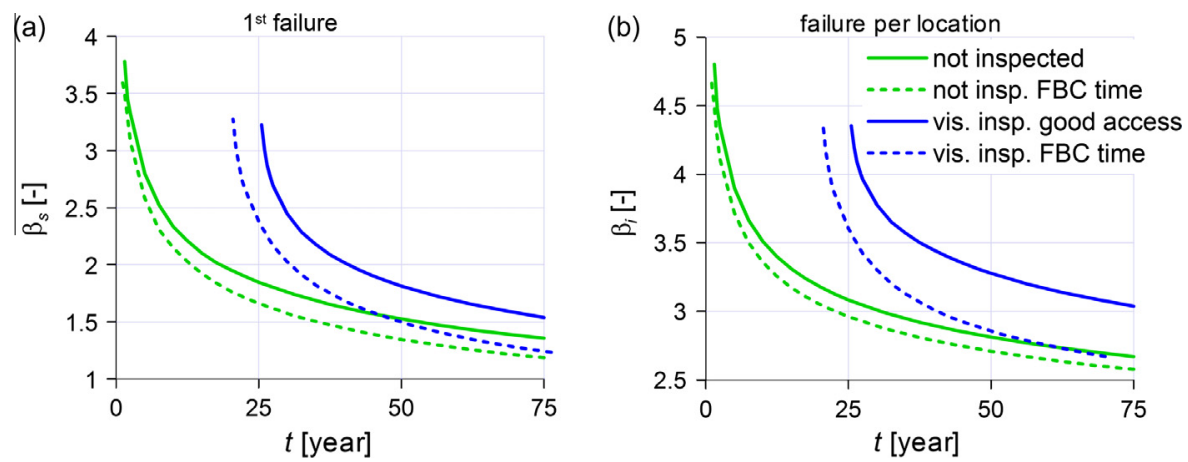

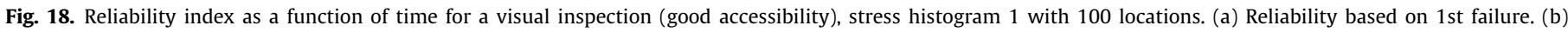
Reliability per location. 
demonstrated by application to an orthotropic bridge deck with 100 stringer-to-crossbeam joints. The following conclusions apply:

- If multiple possible crack locations are present in a structure, it is worth considering spatial correlations in fatigue failure probability calculations. The examples with 100 locations considered in this paper provide an increase in the inspection interval with a factor of more than 2 if spatial correlations are considered.

- Structures such as orthotropic bridge decks are often visually inspected for fatigue cracks. Despite the poor probability of detection (PoD) of such a technique, the inspection interval is reasonable if a minimum inspection reliability can be guaranteed, if spatial correlations are considered, and if the fatigue sensitive details are relatively tolerant to large cracks.

- An inspection in which only a fraction of all possible crack locations are inspected - e.g. $10 \%$ - is of little use: the update of the probability of 1st failure of a location as well as that of the failure probability per location are small, even in case of inspections with high PoD.

- Uncertainties in local stress ranges and stress intensity factors are important factors for the failure probability. These uncertainties should be well evaluated on a case-by-case basis.

- A fatigue crack in a detail exposed to a large number of cycles with variable amplitude tends to grow more progressively than the same detail exposed to a constant (equivalent) stress range. Hence, when accounting for inspections in fatigue failure predictions, it is unsafe to consider a constant (equivalent) stress range in such cases.

- Further study is required on the (intuitive) discrepancy between the bathtub curve generally assumed for fatigue failure and the ever increasing inspection interval resulting from probabilistic crack growth models if cracks are not found during subsequent inspections.

- Further study is also required on the spatial correlation coefficients of some of the variables.

\section{References}

[1] Sangid MD. The physics of fatigue crack initiation. Int J Fatigue 2013;57:58-72.

[2] Moan T. Reliability-based management of inspection, maintenance and repair of offshore structures. J Struct Infrastruct Eng 2005;1:33-62.

[3] Ling Y, Mahadevan S. Integration of structural health monitoring and fatigue damage prognosis. Mech Syst Signal Process 2012;28:89-104.

[4] Sankararaman S, Ling Y, Mahadevan S. Uncertainty quantification and model validation of fatigue crack growth prediction. Eng Fract Mech 2011;78:1487-504.

[5] Grell WA, Laz PJ. Probabilistic fatigue life prediction using AFGROW and accounting for material variability. Int J Fatigue 2010;32:1042-9.

[6] Hemez FM, Roberson AN, Rutherford AC. Uncertainty quantification and model validation for damage prognosis. In: Proc 4th int workshop on structural health monitoring. Stanford: Stanford University; 2003, p. 575-82.

[7] Straub D, Faber MH. Risk based acceptance criteria for joints subjected to fatigue deterioration. J Offshore Mech Arct 2005;127:150-7.

[8] Gregory P. Bayesian logical data analysis for the physical sciences: a comparative approach with mathematica support. Cambridge: Cambridge University Press; 2005.

[9] Madzen HO, Sørensen JD, Olesen R. Optimal inspection planning for fatigue damage of offshore structures. In: Proc. int. conf. on structural safety and reliability. San Fransisco: ICOSSAR; 1989, p. 2099-106.

[10] Faber MH, Engelund S, Sørensen JD, Tychsen J, Straub D. Field implementation of RBI for jacket structures. J Offshore Mech Arct 2005;127:220-6.

[11] Wang X, Rabiei M, Hurtado J, Modarres M, Hoffman P. A probabilistic-based airframe integrity management model. Reliab Eng Syst Safe 2009;94:932-41.

[12] Wu WF, Ni CC. Statistical aspects of some fatigue crack growth data. Eng Fract Mech 2007:74:2952-63.

[13] Sander M, Richard HA. Fatigue crack growth under variable amplitude loading, Part 1: experimental investigations. Fatigue Fract Eng Mater Struct 2006;29:291-301.

[14] Kim S, Frangopol DM. Optimum inspection planning for minimizing fatigue damage detection delay of ship hull structures. Int J Fatigue 2011;33:448-59.
[15] Soliman M, Frangopol DM, Kim S. Probabilistic optimum inspection planning of steel bridges with multiple fatigue sensitive details. Eng Struct 2013;49:996-1006.

[16] Rabiei M, Modarres M. A recursive Bayesian framework for structural health management using online monitoring and periodic inspections. Reliab Eng Syst Safe 2013;112:154-64.

[17] Paris P, Erdogan F. J Basic Eng 1963;85:528-34.

[18] Forman R, Kearney V, Engle R. J Basic Eng 1967;89:459-64.

[19] Newman JC Jr. A crack-closure model for predicting fatigue crack growth under aircraft spectrum loading. In: Methods and models for predicting fatigue crack growth under random loading, ASTM STP 748. Philadelphia: ASTM: 1981, p. $53-84$

[20] Guan X, Jha R, Liu Y. Model selection, updating, and averaging for probabilistic fatigue damage prognosis. Struct Saf 2011;33:242-9.

[21] Zárate BA, Caicedo JM, Yu J, Ziehl P. Bayesian model updating and prognosis of fatigue crack growth. Eng Struct 2012;45:53-61.

[22] Feng GQ, Garbatov Y, Guedes Soares C. Fatigue reliability of a stiffened panel subjected to correlated crack growth. Struct Saf 2012;36-37:39-46.

[23] Sørensen JD, Ersdal G. Risk based inspection planning of ageing structures. In: Proc. OMAE'08, Estoril: ASME; 2008, p. 1-10.

[24] Moan T, Song R. Implication of inspection updating on system fatigue reliability of offshore structures. In: Proc. OMAE'98. Lisbon: ASME; 1998.

[25] Ayala-Uruga E, Moan T. System reliability issues of offshore structures considering fatigue failure and updating based on inspection. In: Proc. 1st int ASRANet colloquium. Glasgow: ASRANet; 2002.

[26] Broek D. Elementary engineering fracture mechanics. 4th ed. Boston: Kluwer academic publishers; 1986.

[27] Anderson TL. Fracture mechanics. 3rd ed. Boca Raton: CLC Press; 2004.

[28] BS 7910:2013. Guide to methods for assessing the acceptability of flaws in metallic structures. BSI, London; 2013.

[29] Maddox SJ, Andrews RM. Stress intensity factors for weld toe cracks. In: Proc. 1 st int conf computer-aided assessment and control of localized damage. Portsmouth: Springer-Verlag; 1990.

[30] Newman JC, Raju IS. Stress intensity factor equations for cracks in three-dimensional finite bodies subjected to tension and bending loads. NASA technical memorandum 85793. Hampton: Langley Research Centre; 1984.

[31] Leendertz JS. Fatigue behaviour of closed stiffener to crossbeam connections in orthotropic steel bridge decks. Delft: Delft University of Technology; 2008.

[32] Beales C. Measurements and interpretation of dynamic loads on bridges - phase 3: fatigue behaviour of orthotropic steel decks of road bridges, final report ECSC agreement number 7210-KD/807. Berkshire: Crowthorne: Transport and Road Research Laboratory; 1989.

[33] JCSS probabilistic model code, part 3: material properties. Aalborg: JCCS; 2000. $<$ http://www.jcss.byg.dtu.dk/>.

[34] Kebir H, Roelandt JM, Gaudin J. Monte-carlo simulations of life expectancy using the dual boundary method. Eng Fract Mech 2001;68:1371-84.

[35] Rosenblatt M. Remarks on a multivariate transformation. Ann Math Stat $1952 ; 23: 470-2$.

[36] Lebrun R, Dutfoy A. Do Rosenblatt and Nataf isoprobabilistic transformations really differ? Prob Eng Mech 2009;24:577-84.

[37] Melchers RE. Structural reliability analysis and prediction. 2nd ed. New York: John Wiley; 1999.

[38] Cortie MB. The irrepressible relationship between the Paris law. Eng Fract Mech 1991;40:681-2.

[39] Zhao Z, Haldar A. Bridge fatigue damage evaluation and updating using nondestructive inspections. Eng Fract Mech 1996;53:775-88.

[40] Carpinteri A, Paggi M. Self-similarity and crack growth instability in the correlation between the Paris' constants. Eng Fract Mech 2007;74:1041-53.

[41] Austen I. Measurement of fatigue crack threshold values for use in design, SH/ EN/9708/2/83/B. London: British Steel Corporation; 1983.

[42] Noordhoek C, Scholte H, Jonkers P, Koning C, Dijkstra O. Fatigue and fracture behaviour of welded joints in high strength steels (FeE 460). Eindhoven: Eindhoven University of Technology; 1993.

[43] Pijpers RJM, Maljaars J, Brekelmans J, Slot H. FaiMoS WP2 - fatigue of steel structures, crack growth tests and simulations. Delft: TNO; 2012.

[44] Ohta A, Suzuki N, Maeda Y. Unique fatigue threshold and growth properties of welded joints in a tensile residual stress field. Int J Fatigue 1997;19-S1:S30310.

[45] Liu Y, Mahadevan S. Probabilistic fatigue life prediction using an equivalent initial flaw size distribution. Int J Fatigue 2009;31:476-87.

[46] Kountouris IS, Baker MJ. The reliability of non-destructive examination of welded joints. London: Imperial College; 1989.

[47] Kountouris IS, Baker MJ. Defect assessment: analysis of the dimensions of defects detected by ultrasonic inspection in an offshore structure. CESLIC Report OR8; 1989.

[48] Nykänen T, Marquis G, Björk T. A simplified fatigue assessment method for high quality welded cruciform joints. Int J Fatigue 2009;31:79-87.

[49] Kolstein MH. Fatigue classification of welded joints in orthotropic steel bridge decks. Delft: Delft University of Technology; 2007.

[50] Maljaars J, Steenbergen HMGM, Vrouwenvelder ACWM. Probabilistic model for fatigue crack growth and fracture of welded joints in civil engineering structures. Int J Fatigue 2012;38:108-17.

[51] Visser P. POD/POS curves for non-destructive examination. Offshore technology report 2000/018. Norwich: Health and Safety Executive; 2002. 
[52] FHWA Reliability of visual inspection for highway Bridges. Volume I, Fina report, FHWA Report No. FHWA-RD-010020. Washington DC: Federal Highway Administration, U.S. Department of Transportation; 2001.

[53] TWI Ltd. NDT capability for the detection and sizing of surface-breaking fatigue cracks in welded steel bridges. Rep No 12539/1/01. In: Fatigue assessment of steel bridge components with existing cracks. Highways Agency Contract 3/284; 2001.

[54] Knorr E. Reliability of the detection of flaws and of the determination of flaw size. Quebec: AGARDograph 1974;176:398-412.

[55] Lewis WH, Sproat WH, Dodd BD, Hamilton JM. Reliability of non-destructive inspection. SA-ALC/MME. 76-6-38-1. San Antonio: San Antonio Air Logistics Centre; 1978.

[56] Mello AWA, Mattos DFV. Reliability prediction for structures under cyclic loads and recurring inspections. J Aerosp Technol Manage 2009;1:201-9.
[57] Righiniotis TD. A comparative study of fatigue inspection methods. J Constr Steel Res 2006;62:352-8.

[58] Morales-Nápoles O, Steenbergen RDJM. Analysis of axle and vehicle load properties through Bayesian Networks based on Weigh-in-Motion data. Rel Eng Syst Safe; in press [2014].

[59] Ludescher H. Berücksichtigung von dynamischen verkehrslasten beim tragsicherheitsnachweis van strassenbrücken. Lausanne: École Polytechnique Fédérale de Lausanne; 2003.

[60] Kwon K, Frangopol DM. Bridge fatigue assessment and management using reliability-based crack growth and probability of detection models. Probabilist Eng Mech 2011;26:471-80.

[61] Sørensen JD, Ersdal G. Safety and inspection planning of older installations. Proc IMechE 2008;222:403-17. 